\title{
Evolución del sistema constitucional de las autonomías territoriales y nuevas relaciones entre los niveles institucionales
}

\author{
Giancarlo Rolla \\ Universidad de Siena
}

\begin{abstract}
Sumario: 1. LA REFORMA DEL SISTEMA INSTITUCIONAL EN AUSENCIA DE UNA REVISIÓN DE LA CONSTITUCIÓN. 2. LA AFIRMACIÓN DE UNA NUEVA NOCIÓN DE AUTONOMÍA CONSTITUCIONAL. 3. LOS TRES PILARES DE LA EVOLUCIÓN DEL SISTEMA CONSTITUCIONAL DE LAS AUTONOMÍAS LOCALES. 4. EL PAPEL DE LAS REGIONES EN LA REDEFINICIÓN DE LOS PERFILES DEL SISTEMA DE LOS PODERES LOCALES. 5. LA REORGANIZACIÓN DEL SISTEMA DE GOBIERNO DE LAS AUTONOMÍAS TERRITORIALES. 5.1. La potenciación de la autonomía estatutaria de las regiones. 5.2. La potenciación de las formas asociativas y de los instrumentos de colaboración entre los entes locales territoriales. 6. UN NUEVO PAPEL PARA EL ESTADO CENTRAL. 6.1. Naturaleza y funciones del poder sustitutivo. 6.2. La supletoriedad de la normativa estatal y la afirmación de la noción de norma cedible.
\end{abstract}

\section{LA REFORMA DEL SISTEMA INSTITUCIONAL EN AUSENCIA DE UNA REVISIÓN DE LA CONSTITUCIÓN}

Los años que van de 1990 a 1999 representan una década de profundos cambios tanto en el sistema de relaciones entre los diversos niveles institucionales en los que se distribuye la República italiana, en el sentido del artículo 14 de la Constitución, como en el planteamiento organizativo de cada uno de ellos.

La legislación rica e innovadora que ha afectado al sistema de las autonomías regionales y locales posee una característica particular, que se puede resumir en el hecho de que ha afectado simultáneamente tanto a la distribución de las competencias como a la organización de los procesos decisorios en el ámbito local: ha logrado enriquecer y perfeccionar el principio constitucional de autonomía.

A título de ejemplo, en el ámbito de las competencias, podemos recordar la Ley 59/97, el Decreto legislativo 112/98 y la copiosa legislación subsiguiente regional de aplicación; en cuanto a los perfiles de los ordenamientos, la atención se debe centrar en las Leyes 142/90, 81/93 y $265 / 99$ en materia de municipios y provincias, y en la Ley constitucional 1/99 en materia de regiones. 
Se trata de un corpus normativo amplio y complejo, que sobre presupuestos nuevos ha delineado el esqueleto institucional del ordenamiento de las autonomías territoriales: se ha propuesto potenciar el papel de las autonomías políticas, acelerar las funciones ejercidas por los aparatos del Estado central y reconfigurar la relación entre el Estado y las regiones sobre bases nuevas en comparación con las codificadas por las establecidas en los años inmediatamente posteriores al segundo conflicto mundial. Más allá de las distinciones nominalistas y de la estéril alternativa entre el federalismo y el regionalismo, la nueva normativa ha tratado de dar la vuelta al sistema de las competencias asignando a las autonomías territoriales una competencia general de tipo residual, frente a poderes estatales enumerados taxativamente; además, superando el principio del paralelismo de las funciones introducido por el artículo 118 de la Constitución, ha identificado en los municipios los títulos privilegiados de la potestad administrativa, en tanto que son constitutivos de la administración más próxima a los ciudadanos.

Las innovaciones introducidas por la legislación ordinaria parecen ser todavía más significativas si se comparan con la falta de conclusión del debate sobre las reformas institucionales y sobre el fracaso del resultado de los intentos realizados por el Parlamento para revisar la carta constitucional.

Por lo que respecta a la redefinición de las relaciones entre el Estado, las regiones y las autonomías locales, en estos últimos años el sistema político se ha encontrado ante una bifurcación: tenía que optar, por un lado, atender a la solución de la deseada reforma constitucional que el parlamento había intentado poner en marcha con la aprobación de la Ley constitucional $\mathrm{n}^{\circ} 1$ de 1997; o bien, por otro lado, optar por introducir cambios inmediatos por medio de la legislación ordinaria, aprovechando los amplios márgenes de discrecionalidad ofrecidos por una normativa constitucional que es genérica en muchos perfiles.

Las implicaciones que conlleva cada una de esas opciones eran evidentes: la reforma constitucional ofrecía una mayor organicidad y permitía replantear radicalmente el modelo de descentralización política e institucional del Estado a la luz de las actuales exigencias; sin embargo, presentaba la incertidumbre de una evolución accidentada e incierta en sus resultados finales. Sin embargo, las reformas legislativas ofrecían la ventaja de una mayor rapidez, pero (inevitablemente) no podían resultar más que fragmentarias, debiendo operar en el seno de los espacios permitidos por el dictado constitucional. 
EVOLUCIÓN DEL SISTEMA CONSTITUCIONAL DE LAS AUTONOMIAS TERRTTORIALES

Como sucede con frecuencia en la realidad política italiana, la duda sobre la estrategia que se debe perseguir ha quedado resuelta más que por una determinación explícita y ponderada del Parlamento, por los propios hechos: el surgimiento de una profunda crisis del proceso decisorio ha bloqueạdo el proceso de reforma constitucional, por lo que no quedaba otra posibilidad que confiar en la actividad normativa del gobierno, al que - sobre la base del Decreto legislativo n. ${ }^{\circ} 29$ de 1997- se había delegado la transferencia de nuevas funciones del Estado a las regiones y a los entes locales.

De este modo, el gobierno se hizo cargo de la laboriosa tarea de reubicar las funciones entre los diversos niveles institucionales de la República según los principios de autonomía y subsidiariedad, así como de fijar nuevas reglas para las relaciones entre el Estado central y las autonomías territoriales. Dicho resultado se logró esencialmente con la aprobación de:

a) el Decreto legislativo 112/98 de «Otorgamiento de funciones y tareas administrativas del Estado a las regiones y a los entes locales», que renovó la distribución territorial de las competencias, determinando de nuevo las tareas legislativas y administrativas de los distintos niveles institucionales (Estado, regiones, entes locales territoriales);

b) el Decreto legislativo 281/97 que, redefiniendo la organización y las tareas de la Conferencia permanente para las relaciones entre el Estado, las regiones y las provincias autónomas de Trento y de Bolzano, dando vida al mismo tiempo a una conferencia entre el Estado y las ciudades y autonomías locales, delineó el esquema de las futuras relaciones entre el Estado y las autonomías territoriales, dotando de reglas, procedimientos y estructuras al principio del regionalismo cooperativo al que en el pasado se apeló desde una jurisprudencia consolidada del Tribunal Constitucional.

Por estas razones podemos afirmar que, a pesar del bloqueo del proceso de revisión de la Constitución, el escenario constitucional italiano se ha modificado profundamente, hasta el punto de que - si observamos la evolución que se está produciendo en el sistema de las autonomías territoriales-Italia se puede considerar un fecundo «laboratorio» de innovación administrativa e institucional, un «observatorio» privilegiado para el estudioso extranjero, atento a los perfiles del Derecho comparado. 


\section{LA AFIRMACIÓN DE UNA NUEVA NOCIÓN DE AUTONOMÍA CONSTITUCIONAL}

Más allá del detalle de la reciente normativa que ha reformado el sistema de distribución de las competencias entre el Estado central, las regiones y las autonomías locales, previamente hay que subrayar que, en su conjunto, la legislación se cualifica por el esfuerzo de dotar de sustancia a una nueva noción de autonomía constitucional de las comunidades territoriales.

Parece que se está superando una visión de la autonomía influida, por un lado, por la importancia asumida —en el pasado-por las teorías estatalistas, que reconocían al Estado una posición de predominio en cuanto que es el único ente titular del ejercicio de la soberanía; por otro lado, por los principios que son la base del Estado liberal de Derecho, entendido en su dimensión de Estado legislativo, concretamente por aquellas posturas que afirman la supremacía de la ley sobre la administración y subrayan el carácter necesariamente unitario de la administración como cuerpo homogéneamente destinado a la especificación de la voluntad general expresada por el legislador.

Los primeros habían inducido a defender que todos los poderes deben encontrar su propio fundamento en la ley: por eso sólo se pueden manifestar dentro de los confines y según los modos y las reglas determinados por la ley. La naturaleza sustancialmente unitaria de la administración, a su vez, requería que todos sus actos fuesen coherentes con la voluntad general del Estado y, por lo tanto, sin poderse oponer a ella, siempre se debían subordinar a los generales hechos valer por el Estado.

En consecuencia, la autonomía, con mucho, se había relegado y reducido a la categoría de las formas de organización de un ente público; se consideraba un modo particular de organización para un ente, expresaba la postura de un ente en el seno de la organización estatal.

Pero la imagen de la autonomía también se puede delinear por un perfil distinto y opuesto que, más que las relaciones que se establecen entre el Estado y sus ordenamientos internos, procura considerar la organización que una determinada comunidad - una porción del pueblo- es capaz de verse sobre la base territorial. De este modo, la autonomía representaría la forma que tiene una comunidad determinada de organizarse en el territorio; constituiría el reconocimiento de la subjetividad institucional de las distintas comunidades. 
En consecuencia, resulta dificil adecuar los procesos de decisión a la existencia de un pluralismo hecho de distintas identidades, de diferencias territoriales que tratan de valorizarse; como tal, representa un valor que las Constituciones codifican para lograr la integración política de las comunidades sociales en el seno del Estado, para identificar los instrumentos y las instituciones que, en una realidad pluralista y policéntrica, permiten lograr la unidad del Estado por medio de la adhesión de su sustrato comunitario.

Por otra parte, esta visión comunitaria de las autonomías territoriales surge de la propia Carta Europea de la Autonomía Local, firmada en Estrasburgo el 15 de octubre de 1985 y ratificada en Italia con la Ley 439/89.

De hecho, esta Carta, después de afirmar en el preámbulo que «las colectividades locales constituyen uno de los principales fundamentos de cualquier régimen democrático», dispone (art. 3) que "por autonomía local se entiende el derecho y la capacidad efectiva para las colectividades locales de reglamentar y administrar en el ámbito de la ley, bajo su propia responsabilidad y a favor de los pueblos, una parte importante de los asuntos públicos».

Además, la Carta Europea ha subrayado otros dos aspectos: por un lado, ha precisado que «las colectividades locales, en el ámbito de la ley, tienen las más amplias facultades para tomar iniciativas propias en cualquier cuestión que no se salga de su competencia o esté asignada a otra autoridad»; por otro lado, han previsto que «el ejercicio de las responsabilidades públicas, por principio, debe incumbir preferentemente a las autoridades más próximas a los ciudadanos. La asignación de una responsabilidad a otra autoridad debe tener en cuenta la amplitud y la naturaleza de la tarea y las exigencias de eficacia y economía».

Por lo tanto, de esta definición surge el estrecho vínculo tanto con las colectividades locales como entre la autonomía local y el autogobierno: en el sentido de que una gran parte de las funciones que afectan a las colectividades locales se deben poder gestionar por los representantes de éstas.

Seguramente el artículo 2.1 de la Ley $265 / 99$ se inspira en una visión comunitaria de las autonomías, cuando precisa que «el municipio es el ente local que representa a su propia comunidad», añadiendo a esta afirmación aquella otra de que «se ocupa de los intereses y promociona el desarrollo»: así, permite una lectura evolutiva del dictado constitucional de la que se puede recrear el vínculo indisoluble entre autonomía y territo- 
rialidad, interpretando el artículo 5 de la Constitución, en relación con el artículo 2 de la misma, allí donde valora la proyección social de la persona, en la consideración de que ésta se manifiesta no sólo en clave asociativa, sino también sobre base territorial. De este modo se concreta a escala legislativa una de las interpretaciones apuntadas por la doctrina en el artículo 5 de la Constitución, según la cual la referencia a la autonomía que contiene dicho artículo, situado entre los principios fundamentales de nuestra Constitución, se debe considerar referido a las comunidades locales, para las cuales serían exponentes las entidades que menciona el artículo 114 (regiones, provincias y municipios).

Coherentes con las orientaciones formuladas por la Carta Europea de la Autonomía Local, se presentan también los principios inspiratorios de la Ley 59/97 y del Decreto legislativo 112/98, los cuales, destacando el esquema hasta ahora predominante de distribución de competencias, identifican en las entidades representativas de las autonomías territoriales a los sujetos dotados de una competencia general, y en particular atribuyen a la autonomía de base del sistema italiano de gobierno local - los municipios- la medida principal de las competencias administrativas, siempre que sea compatible con el principio de subsidiariedad.

Además, las modalidades establecidas por dicha normativa para otorgar a las regiones y a las entidades locales nuevas funciones y nuevas tareas, resultan ser respetuosas con algunas cualidades que algunos sectores de la doctrina - fundamentalmente atentos a las transformaciones que se producen - han indicado para constituir el D.N.A. del principio constitucional de autonomía. Se trata de elementos que cada ordenamiento que se inspire en el principio de autonomía puede organizar y modular de modo diverso, pero no puede dejar de lado, so pena de negar el carácter autonomista del sistema.

En primer lugar, la autonomía presupone la existencia de un poder dispositivo efectivo en cuanto a los contenidos y las características de la propia autonomía. En segundo lugar, autonomía también es participación y concurso en la determinación de los principios comunes sobre los que se fundamenta el carácter unitario de un ordenamiento.

Finalmente, la autonomía es tal si el sujeto que goza de dicho status está dotado de instrumentos eficaces destinados a la tutela de sus propios ámbitos de competencia.

Teniendo en el fondo estas connotaciones que cualifican la noción de autonomía, se puede interpretar la legislación más reciente en materia de 
EVOLUCIÓN DEL SISTEMA CONSTITUCIONAL DE LAS AUTONOMIAS TERRITORIALES

autonomía regional y local como el intento - por demás todavía incumplido, y con lagunas en ciertos sentidos- de dotar a dichos atributos de un soporte normativo y de un instrumento operativo.

En coherencia con el principio dispositivo, entendido como la capacidad de disponer de las características del ordenamiento de la comunidad que se representa, se puede considerar la opción de atribuir a las fuentes de autonomía (especialmente a las leyes regionales y a los reglamentos de los entes locales) la identificación de las funciones administrativas específicas que cada autonomía territorial debe ejercer.

Entre la autonomía constitucional de los entes locales y las atribuciones que les competen existe un estrecho vínculo desde el momento en que la primera, para poderse manifestar debidamente, necesita un conjunto adecuado de funciones que ejercer. Si la autonomía, considerada como una relación entre varios ordenamientos, se manifiesta sobre todo bajo forma de límites a las posibles injerencias por parte de sujetos externos, también es indudable que la autonomía, como posibilidad de autodeterminarse, también se traduce en la posibilidad de reglamentar (o, mejor, autorreglamentar) los sectores de su propia competencia.

Distinguiéndose de la anterior experiencia de descentralización y de trasferencia de las funciones, en la que el legislador nacional había procedido directamente a determinar analíticamente las funciones que corresponden a los distintos entes descentralizados, la Ley 59/97 otorga tal competencia a las regiones y, al mismo tiempo, obliga a dichas entidades a realizar la opción involucrando a las entidades locales afectadas. Por un lado, de hecho, el artículo 4.1 de la citada ley dispone que, en las materias que trata el artículo 117 de la Constitución, compete a las regiones «otorgar a las provincias, a los municipios y a los demás entes locales todas las funciones que no requieran el ejercicio unitario a escala regional»; por otro lado, en el mismo párrafo se obliga al legislador regional a oír a «las representaciones de los entes locales» ante los correspondientes «órganos representativos de las autonomías locales establecidos por las leyes regionales».

Esta característica de la legislación también satisface el principio participativo - que constituye un elemento adicional que cualifica el principio de autonomía - sobre cuya base hay que garantizar a las autonomías territoriales una participación efectiva en la definición de los principios y de las normas susceptibles de actuar como parámetro en la distribución de las correspondientes esferas de atribución. 
Este principio representa una especificación del criterio más general de leal colaboración, que - según la jurisprudencia del Tribunal Constitucional- debe informar las relaciones entre los distintos niveles institucionales. De esta característica hablaremos más ampliamente en el capítulo siguiente; sin embargo, de momento no se puede dejar de subrayar que el legislador ha previsto diversos mecanismos y órganos destinados a mejorar las relaciones intergubernamentales y, en consecuencia, la participación de las autonomías en los procesos decisorios, pasando de una noción de autonomía «competitiva» a otra de tipo «concertativo». Esta lógica concertativa adopta en el sistema italiano una dirección institucional, diferenciándose con ello - si no me equivoco- de la realidad española, donde los pactos autonómicos, que han sido la base del proceso de constitución del Estado autonómico, tenían una naturaleza predominantemente prejurídica y política, y en cuanto a sus contenidos se podrían centrar más en un acuerdo constitucional que en una auténtica fuente legal escrita.

Dichos mecanismos de concertación expresan, en definitiva, una decidida opción del sistema italiano de las autonomías territoriales hacia formas de garantía más políticas que jurisdiccionales. Con esta opción se entra por tanto en un tercer perfil que caracteriza la noción constitucional de autonomía, es decir, en la existencia de instrumentos y mecanismos de defensa frente al legislador.

La tutela constitucional de la autonomía, en general, se percibe por dos caminos, uno de ellos formado por la jurisdicción nacional y el otro por la mediación institucional. Se trata de dos soluciones no alternativas, como demuestra la propia Ley Orgánica española 1/2000; sin embargo, es indudable que poseen un valor muy diferente.

En el primer caso se confia en los jueces, sobre todo en los constitucionales, para resolver en asuntos concretos el contencioso que se produce entre los distintos niveles institucionales, ya sea para retomar, en el examen de las orientaciones jurisprudenciales consolidadas, el parámetro al que referirse con objeto de definir, en los distintos ordenamientos, el equilibrio entre el Estado central y las comunidades descentralizadas. La segunda solución es de naturaleza más política y se basa en la definición de procedimientos de pacto para alcanzar una definición concordada en la distribución de competencias, que pueden tener resultados generales cuando se definen ámbitos de competencia válidos para todas las regiones, o individuales cuando la fase de negociación implique a una sola región. 
Teniendo como referencia este escenario es indudable que el sistema italiano - y en esto probablemente se distingue del español- ha privilegiado decididamente la vía de la mediación y del entendimiento institucional.

La tutela jurisdiccional de las autonomías constitucionales, que en el caso de las regiones se manifiesta esencialmente a través del juicio de legitimidad constitucional por la vía de la acción y el conflicto de atribuciones, no existe en absoluto en el caso de los entes locales, a los que les faltan formas eficaces de acceso al Tribunal Constitucional a través de leyes (estatales y regionales) consideradas lesivas de la autonomía constitucional garantizada por los artículos 5 y 128 de la Constitución.

Los instrumentos de los que disponen actualmente los entes locales - faltando la posibilidad de un recurso directo como en España - son esencialmente dos, $\mathrm{y}$ ambos poco satisfactorios:

a) el poder de presentar, como partes de un juicio, una cuestión de legitimidad constitucional frente al juez para que éste, si concurren las condiciones, la transmita al Tribunal Constitucional;

b) la facultad de participar como partes en un proceso constitucional ya establecido.

En cuanto al primer remedio existen múltiples obstáculos para la utilización del juicio incidental para la defensa de la autonomía local: por ejemplo, se considera que no todas las leyes son impugnables por vía incidental (en particular surgen dificultades para las leyes de organización y de principios) y que, de todos modos, esta impugnación sólo se podría producir posteriormente a la entrada en vigor de la ley.

Por otra parte, sigue siendo necesaria la mediación del juez en la identificación de la cuestión y en la valoración de la importancia y de la falta de fundamentos no manifiesta.

En cuanto a la posibilidad de constituirse en parte en el proceso constitucional, no se puede desdeñar que, por un lado, esta posibilidad queda excluida según la jurisprudencia habitual en los juicios por vía principal; por otro lado, que incluso en los casos donde el ente local tiene legitimidad para intervenir en el proceso constitucional (o en los juicios por vía incidental cuando es parte en el proceso a quo), las actividades que puede desarrollar en calidad de sujeto constituido son limitadas y, desde luego, no son suficientes para proporcionar una garantía efectiva de la autonomía local. 
Baste con pensar que los sujetos constituidos ante el Tribunal pueden ilustrar la cuestión de constitucionalidad, pero ésta queda circunscrita a los términos definidos en la ordenanza de remisión: no compete en modo alguno a los municipios ni a las provincias incidir en los thema decidendi.

También parece impracticable la utilización, en función de la defensa de la autonomía local frente al legislador, del instrumento del conflicto entre poderes del Estado, teniendo en cuenta que la jurisprudencia constitucional, en los no numerosos casos en los que el tribunal ha tenido que decidir sobre la admisibilidad de este tipo de recursos, se ha decantado decididamente por la inadmisibilidad. Se trata de una posición que no se puede compartir del todo cuando se recuerda que los municipios y las provincias son entes que representan la voluntad y los intereses de las comunidades territoriales, es decir, son poderes del Estado de comunidades.

\section{LOS TRES PILARES DE LA EVOLUCIÓN DEL SISTEMA CONSTITUCIONAL DE LAS AUTONOMÍAS LOCALES}

\section{a) Nuevos criterios de distribución de las competencias entre Estado central, regiones y entes locales}

Entre la autonomía constitucional de los entes locales y las atribuciones que les competen subsiste un estrecho vínculo desde el momento en que la primera, para poder manifestarse adecuadamente, necesita un conjunto adecuado de funciones que ejercer. Si la autonomía, considerada como una relación entre varios ordenamientos, se manifiesta sobre todo bajo forma de límites a las posibles injerencias por parte de sujetos externos, también es indudable que la autonomía, como posibilidad de autodeterminarse, también se traduce en la posibilidad de reglamentar (o, mejor dicho, de autorreglamentar) los sectores de su propia competencia.

En cuanto a las soluciones estratégicas adoptadas por el legislador italiano en la Ley 59/97 y en el Decreto 112/98, se caracterizan por una doble opción que se puede resumir respectivamente así:

a) en el cambio de criterio de referencia en la distribución de las competencias entre los distintos niveles institucionales;

b) en la realización no tanto de una integración de la descentralización normativa, como de un replanteamiento orgánico del sistema de las competencias, que ha permitido redefinir el papel de cada sujeto. 
Por lo que respecta al primer perfil, en los ordenamientos en cuyo seno existe una distribución sobre base territorial del poder de decisión política la Constitución recurre normalmente a la técnica de los listados y los catálogos de materias, compilados según modelos distintos:

a) según el sistema de la doble lista, sobre cuya base se enumeran la tareas que corresponden respectivamente al Estado y a las regiones;

b) el sistema de la enumeración de las competencias centrales, que trastoca la técnica anterior y enumera las materias que pertenecen a la competencia propia del Estado, mientras que en las restantes materias se presume que la competencia corresponde a los entes descentralizados;

c) el sistema de enumeración de las competencias descentralizadas, que prevé que la Constitución indica las tareas propias de las regiones, reservando las demás por vía residual al legislador estatal.

Mientras que los artículos 117 y 118 de la Constitución habían optado por este último modelo, la Ley 59/97 ha hecho propio el criterio de la enumeración de las competencias del Estado central, aunque con algunas correcciones. En consecuencia, bajo el perfil de las competencias administrativas, la ley ha definido una lista de materias cuyas funciones siguen siendo de interés estatal (desde asuntos exteriores hasta la defensa, desde la tutela de los bienes culturales hasta las políticas de ciudadanía; desde la moneda hasta la materia electoral; desde la seguridad pública hasta la administración de justicia; desde la investigación científica hasta las telecomunicaciones; desde la educación escolar hasta la previsión social, etc.), mientras que deben considerarse competencia de las regiones y de los entes locales todas las restantes funciones y las tareas administrativas correspondientes a la tutela de los intereses y a la promoción del desarrollo de las comunidades respectivas (art. 1.2).

Como se verá con más detalle a continuación, la definición efectiva del nivel institucional local más idóneo para el ejercicio de estas últimas actividades no la realizará directamente el Estado, sino que se confia a las regiones, que deberán aprobar las leyes correspondientes en función de algunos principios y criterios directivos, como por ejemplo los de subsidiariedad, integridad, adecuación y diferenciación.

Por lo que respecta al segundo perfil —es decir, un replanteamiento radical del sistema de autonomías territoriales con la subsiguiente recalificación del papel de cada una de ellas - hay que considerar que se ha pa- 
sado de una condición estática a otra de dinamismo en la distribución de las competencias.

Antes de la aprobación de la Ley 142/90 —en el sentido de la VIII disposición transitoria de la Constitución - el sistema de las competencias era estático en el sentido de que el legislador podía atribuir nuevas competencias, pero no redistribuir las que ya estaban asignadas a los municipios y a las provincias. Por el contrario, la legislación más reciente se ha propuesto reordenar el sistema de las competencias, incluso transfiriéndolas de un ente local a otro.

El paso de la primera a la segunda fase se ha producido con la entrada en vigor de la Ley 142/90, desde el momento en que las disposiciones contenidas en los artículos 9 y 14 han identificado, por un lado, en el municipio al ente local dotado de una competencia administrativa general y, por otro lado, ha considerado tanto a las regiones como a las provincias entes con competencia administrativa sectorial.

Luego esta opción se ha precisado mejor con el Decreto legislativo $112 / 98$ sobre otorgamiento de funciones administrativas, que ha reservado a las regiones las «únicas funciones que requieren el ejercicio unitario a escala regional».

\section{b) El principio de leal cooperación}

Las relaciones entre el Estado y los entes dotados de autonomía durante mucho tiempo han estado marcadas por una óptica estrictamente competitiva, que se proponía realizar la autonomía con la introducción de una separación neta de las competencias. Por lo tanto se privilegió la distinción más que la integración.

En consecuencia, en el período inicial de construcción del sistema de las autonomías regionales el interés principal se dirigió, por un lado, a determinar los criterios utilizables para identificar las materias de competencia respectiva; por otro lado, al perfeccionamiento de los instrumentos políticos y jurisdiccionales que se podían utilizar para resolver los posibles conflictos. Sin embargo, quedaron en la sombra los perfiles del dictado constitucional que atendían no tanto a la garantía de las correspondientes esferas de competencia, sino más bien a la exigencia de coordinación: como es el caso del artículo 118 de la Constitución -que introduce en las mismas materias una distribución de tareas entre el Estado, la región y los entes locales territoriales sobre la base de la dimensión de los 
intereses (nacionales, regionales y locales)—, del artículo 119 de la Constitución -que plantea el problema de la coordinación de las finanzas respectivas-, del artículo 124 de la Constitución -que entre las tareas del Comisario del Gobierno identifica también la de coordinar las funciones administrativas ejercidas por el Estado con la de la región-, y de las diversas disposiciones de los estatutos especiales que prevén la participación de representantes regionales en reuniones deliberadoras de organismos gubernamentales.

En la fase madura del autonomismo se ha manifestado sin embargo una neta inversión de la tendencia, ahora hacia la afirmación de un modelo de relaciones interinstitucionales basado en el principio de la colaboración.

En nuestro ordenamiento, el paso de un autonomismo en sentido dual a uno de tipo cooperativo ha estado inicialmente favorecido por la jurisprudencia del Tribunal Constitucional, que ha introducido el principio de la leal colaboración. El juez constitucional -en varias ocasiones- ha afirmado que las relaciones entre el Estado, las regiones y las autonomías locales deben estar caracterizadas por criterios de paridad y de lealtad recíproca, sobre la base de procedimientos que aseguren un equilibrio adecuado entre la acción de los organismos estatales y las competencias regionales y locales. En concreto, el Tribunal Constitucional ha intentado compaginar una doble exigencia: por un lado, asegurar la funcionalidad de la intervención pública evitando inercias y vacíos; por otro lado, evitar que todo esto se traduzca en una compresión sustancial de las competencias locales. En el primer frente ha reconocido la constitucionalidad de las intervenciones sustitutivas del gobierno en caso de inercia de las regiones y de los entes locales en las actuaciones a las que obliga la ley.

La afirmación del autonomismo cooperativo se ha logrado después con la decidida intervención del legislador, que ha disciplinado institutos, organismos y procedimientos adecuados para establecer una estrecha red de relaciones entre los distintos niveles de gobierno.

En este sentido se puede distinguir - gracias a las aportaciones de la doctrina- entre coordinación y cooperación.

La coordinación entre los distintos niveles gubernativos presupone la existencia de un ente al que se atribuye un papel preponderante - una especie de primus inter pares-, y a través de estas actividades se trata de garantizar la funcionalidad de todo el sistema, haciendo que sean compatibles la autonomía de los niveles institucionales y la unidad del ordena- 
miento, evitando que las comunidades territoriales caigan en inercias y que no se produzca la parálisis del sistema (a lo largo del capítulo sexto profundizaremos especialmente en la evolución que ha experimentado un instrumento de coordinación específico como es la intervención sustitutiva en caso de inactividad persistente por parte de las autonomías territoriales).

A su vez, la cooperación presupone la equiparación entre todos los actores implicados en las relaciones: los perfiles de jerarquía se atenúan para dejar espacio a los correspondientes a la concertación - sobre base de igualdad - de todos los participantes. Las relaciones de fuerza entre los distintos niveles institucionales no se merman, pero tienden a diluirse tanto en el seno de los organismos mixtos (compuestos por representantes de todos los niveles institucionales) como en la determinación de procedimientos cuyas reglas determina por consenso cada uno de los componentes.

\section{c) La introducción del principio dispositivo en la distribución de las competencias}

La distribución concreta de las competencias en el seno del ordenamiento republicano ha estado condicionada por el convencimiento -que, por otro lado, se fundaba en las aportaciones teóricas de la doctrina administrativa, de mayor autoridad- de que la ley es la fuente legitimante de los poderes de los sujetos dotados de autonomía, en el sentido de que de ella dependen el objeto, los modos de manifestación y los límites de la autonomía. De ello se deduce que la autonomía, en lugar de representar un límite a la discrecionalidad del legislador, tiende a ser considerada más bien como un objeto de la acción legislativa: al convertirse en una limitación que la ley se impone a sí misma, no estaríamos tanto ante un límite para la ley, sino más bien frente a la expresión de un poder discrecional a través del cual se autolimita dicha fuente.

Pero en ese caso el principio de autonomía - en la medida en que está constitucionalizado- corre el riesgo de quedar privado de una garantía constitucional sustancial, reduciéndose a ser una "página en blanco» sobre la que el legislador puede modular, con amplios márgenes de discrecionalidad, las atribuciones de las autonomías territoriales tanto en el ámbito de las competencias como en cuanto a la determinación de sus poderes de organización. Sobre todo es así en un sistema como el italiano, en el que no existen remedios jurisdiccionales eficaces para la tutela directa de las autonomías territoriales ante el legislador. 
Advirtiendo dicho peligro, el sistema italiano ha evolucionado, por un lado, reconfirmando el papel central de la ley en la distribución de las competencias entre los distintos niveles institucionales y, por otro lado, tratando de compaginar dicha norma con el principio dispositivo, que presupone una coparticipación efectiva de las autonomías territoriales en la definición de sus propias tareas. El punto de equilibrio se ha conseguido reconociendo la participación de las autonomías territoriales en el proceso de formación de la ley: por eso los contenidos normativos son siempre menos el fruto de la voluntad autónoma de las asambleas legislativas y cada vez más el resultado de un acuerdo entre el Estado central y las autonomías territoriales.

Las disposiciones de ley se convierten en expresión, aunque en una acepción profundamente distinta a la que indican los teóricos del Estado constitucional liberal, de la voluntad general de la República (de un Estado articulado en regiones, municipios y provincias).

En distintos ordenamientos, la participación de las autonomías territoriales en las opciones legislativas se manifiesta a través de la regionalización de una de las dos Cámaras; sin embargo, en Italia se ha preferido ir por un camino diferente. Por un lado, se ha privilegiado el desarrollo de formas de coordinación intergubernamentales; por otro, se ha ampliado la importancia de la actividad legislativa del gobierno, sobre todo potenciando y cualificando la delegación legislativa.

No es casual que la disciplina primaria en materia de relaciones entre el Estado y las autonomías territoriales está casi por completo contenida en decretos legislativos del gobierno, que se han elaborado - según las prescripciones de la ley de delegación - de acuerdo o con la participación del principal órgano de mediación institucional que opera en el ordenamiento constitucional italiano, la Conferencia Estado-regiones. Por ejemplo, el artículo 6 de la Ley 59/97 ha previsto que el gobierno recabe, sobre esquemas de decretos legislativos de otorgamiento de funciones a las regiones, los municipios y las provincias, la opinión no sólo de las correspondientes comisiones parlamentarias, sino también de la Conferencia permanente para las relaciones entre el Estado, las regiones y las provincias autónomas de Trento y de Bolzano, y de la Conferencia Estado-ciudades y autonomías locales, ampliada con los representantes de los municipios montañeses.

A su vez, las regiones, con objeto de ubicar las funciones en el ámbito local, deben oír el parecer de las representaciones de los entes locales territoriales, así como de los instrumentos permanentes de colaboración en- 
tre las regiones y los entes locales que se puedan establecer (art. 3.5 del Decreto 112/98).

\section{EL PAPEL DE LAS REGIONES EN LA REDEFINICIÓN DE LOS PERFILES DEL SISTEMA DE LOS PODERES LOCALES}

Para distribuir las competencias entre los distintos niveles institucionales, el legislador ha concebido un mecanismo de otorgamiento en varias fases, que se puede comparar con la acción de un buscador de oro que introduce su propia criba en la arena de un torrente y, agitando la criba, deja caer la tierra y la arena, reteniendo para sí las briznas de oro.

En primer lugar, compete al Estado identificar las funciones de su propia competencia, solicitando el ejercicio de las demás a las autonomías locales: esta operación se ha cumplido directamente con la Ley 59/97 y con el Decreto legislativo 112/90 (títulos II, III, IV y V) por lo que respecta a las materias que no entran en la competencia legislativa de las regiones en el sentido del artículo 117 de la Constitución.

Por lo tanto, el poder de ubicación pasa a las distintas regiones, las cuales previamente deben identificar las funciones que - por su naturaleza y por las características de los intereses implicados - debe ejercer directamente, confiando todas las demás al sistema de gobierno local (municipios y provincias).

Finalmente, la región debe decidir a qué entes locales se han de atribuir las funciones residuales, es decir, las que no están ejercidas por el Estado ni por las regiones. Para ello no goza de una discrecionalidad plena, en cuanto que el acto de organizar el ejercicio de las funciones propias de los entes locales territoriales está sujeto a un doble orden de límites.

El primero de ellos consiste en el respeto de los criterios directivos definidos por el legislador, que consisten esencialmente en los principios de:

- subsidiariedad, por el que, en la medida de lo posible, las funciones deben ser ejercidas por el ente más próximo a los intereses que se han de reglamentar;

- integridad, según el cual el otorgamiento debe realizarse de forma orgánica, de modo que a cada ente se le asignen todas las funciones que pertenecen a un determinado sector material; 
- cooperación entre los distintos niveles de gobierno en función del principio de leal colaboración;

- adecuación, en el sentido de que se debe tener en cuenta la idoneidad de las distintas tipologías de ente, que debe ejercer sustancialmente determinadas funciones de forma adecuada;

- diferenciación, reconociendo la posibilidad de soluciones territorialmente diferenciadas.

El segundo se puede resumir en la obligación de tener en cuenta la especificidad de cada ente local, tal y como se ha definido en la Ley 142/90.

En función de ella el municipio, que tiene una mayor radicación social, representa el ente comunitario por excelencia, dotado de competencias generales: el municipio se puede considerar un ente capaz de representar a la generalidad de los intereses de la colectividad local. De hecho, según el artículo 2 de la Ley 142/90, el municipio es el ente local que representa a su propia comunidad, se ocupa de sus intereses y promociona el desarrollo; el artículo 9 de esa misma ley precisa, a su vez, que competen a los municipios todas las funciones administrativas que afectan a la población y al territorio municipal, principalmente en los sectores orgánicos de los servicios sociales, del asentamiento y la utilización del territorio y del desarrollo económico. A su vez, el Decreto 112/98, al determinar la asignación de funciones ente los distintos niveles institucionales, ha tomado como base el criterio de que el ejercicio de las funciones administrativas debe competer prioritariamente a las administraciones municipales, en tanto que representan la institución más próxima a los ciudadanos y, por lo tanto, potencialmente son más capaces de interpretar las necesidades.

La afirmación de la provincia como ente autónomo ha seguido sin embargo un itinerario más diferenciado y menos lineal: de hecho, este ente nació como circunscripción territorial del Estado con objeto de asegurar un ejercicio descentralizado de las funciones administrativas estatales, mientras que sólo después puede dotarse de sus propios órganos electores, representativos de la comunidad provincial y que exponen sus intereses. La Ley 142/90 no ha calificado la provincia como ente de competencia general o residual, puesto que sus funciones tienen un límite no sólo en la dimensión provincial del interés, sino también en el conjunto de materias contenido en el artículo 14 de la Ley 142/90.

Según la ley, en el nuevo ordenamiento de las autonomías locales corresponden a la provincia las funciones administrativas de interés provin- 
cial que, en cuanto a algunos sectores materiales, afectan a amplias zonas intermunicipales o a todo el territorio provincial. Se sitúan bajo esta perspectiva tanto el artículo 2 de la Ley 142/90, que define la provincia como un ente intermedio entre el municipio y la región, como el artículo 15 , que atribuye a la provincia la tarea de preparar los planes de coordinación.

A la luz de estos criterios orientadores, la actividad de las regiones en cuanto a la distribución de las competencias administrativas en el ámbito local se desarrolla en varios planos, lógicamente diferenciados:

1. $\quad$ En primer lugar, considerando el hecho de que los municipios son los entes locales de competencia general, deben determinar las funciones específicas que corresponden a las provincias, reservando por lo tanto las que quedan a las administraciones municipales. Esto se produce aplicando el principio de subsidiariedad.

2. Por lo tanto, aplicando el principio de adecuación, deben valorar si atribuir las demás funciones directamente a los distintos municipios, 0 bien introducir formas, incluso coactivas, de cooperación entre entes locales, destinadas a la realización de un sistema eficaz.

Con las más recientes opciones institucionales codificadas por el legislador, las regiones se ven finalmente obligadas a salir del cono de sombra correspondiente a sus competencias en materia de organización del sistema de gobierno local, adonde lo habían relegado, por un lado, la indeterminación del texto constitucional y, por otro, los contrastes entre las regiones y los entes locales territoriales.

De hecho, en el texto de la Constitución las relaciones entre las regiones y los entes locales territoriales se presentan totalmente desenfocadas. Si se excluye la referencia del artículo 118 de la Constitución a la posibilidad de delegar funciones administrativas regionales y la atribución a un órgano de la región del control sobre los actos de los municipios y las provincias (art. 130 de la Constitución), no aparece ninguna referencia significativa a las relaciones entre la región y los entes locales territoriales. Esto confirma el hecho de que los agentes constituyentes delinearon un sistema binario regido por relaciones recurrentes en el Estado y las regiones y entre el Estado y los entes locales.

En otros términos, se puede afirmar que nuestros redactores de la Constitución, por un lado, delinearon un modelo de descentralización estático, que pivota en el centralismo del Estado considerado como único regulador de las competencias y de la organización de los ordenamientos 
jurídicos internos; por otro lado, consideran a los entes dotados de autonomía constitucional no en función de un sistema orgánicamente coordinado, sino como la suma de una multiplicidad de sujetos que no se comunican, más aún, que están en posición de competencia recíproca.

En efecto, bajo el perfil de las competencias administrativas, las relaciones entre las regiones y los entes locales territoriales se han caracterizado fundamentalmente - si no exclusivamente - en términos de competencia. En particular, la competencia administrativa de las regiones ha sido erosionada sensiblemente por los entes locales territoriales: esto ha sido posible desde el momento en que, mientras la dimensión cuantitativa de la potestad legislativa regional está preestablecida por el artículo 117 de la Constitución, la actividad administrativa de las regiones está fuertemente condicionada por las opciones del legislador estatal, quien puede atribuir directamente a los municipios y a las provincias diversas funciones si las considera de interés local.

Un esfuerzo apreciable en la dirección de una ubicación más definida de las regiones en el sistema de gobierno local lo realizó tanto la Ley 142/90 como el Decreto legislativo 112/98, los cuales determinan en las regiones el centro propulsor y de coordinación de todo el sistema de las autonomías locales: en el sentido de que, en las materias que corresponden a la competencia regional en el sentido de los artículos 117 y $118 \mathrm{de}$ la Constitución, a las regiones se les asigna una tarea de dirección en la distribución de las funciones administrativas entre los distintos niveles de gobierno local. La ley les atribuye la función de distribuir, sobre la base del criterio de la dimensión de los intereses, el conjunto de las funciones administrativas entre ellas, los municipios y las provincias.

$\mathrm{Al}$ hacer esto, la región podrá «calibrar» las funciones según las características de la población y del territorio.

\section{LA REORGANIZACIÓN DEL SISTEMA DE GOBIERNO DE LAS AUTONOMÍAS TERRITORIALES}

Una de las características de la actual fase de evolución del sistema de las autonomías en Italia está constituida por saber que una fuerte descentralización de funciones a favor de las autonomías territoriales no determinaría una mejora cualitativa de los servicios y de las prestaciones públicas, a menos que no estuviese también acompañada por una mejora en la organización, tanto de los ordenamientos regionales como del sistema de gobierno local. 
Con tal conciencia, el legislador no se ha limitado a redistribuir las funciones entre los distintos niveles institucionales, sino que también ha aprobado algunas leyes significativas de reforma de la organización de los entes dotados de autonomía constitucional. En particular se señalan la Ley constitucional $1 / 99$ sobre la autonomía organizativa y estatutaria de las regiones, la Ley 142/90 y la Ley $91 / 93$ en cuanto a la forma de gobierno de los municipios y de las provincias, y la Ley $265 / 99$ sobre la incentivación de los instrumentos de coordinación y de asociación entre los entes locales.

\subsection{La potenciación de la autonomía estatutaria de las regiones}

En el caso de las regiones, el legislador ha tratado sobre todo de valorar su poder de autodeterminación, sabiendo que la autonomía organizativa, en cuanto que «diseño preordenado de oficinas y sus atribuciones», está constituida por dos perfiles fundamentales: por un lado la potestas instituendi, es decir, la capacidad de crear, modificar y suprimir oficinas y organismos; por otro lado, la competencia para distribuir las atribuciones entre ellos.

En consecuencia, se ha actuado para ampliar y cualificar la naturaleza y el objeto de la autonomía estatutaria de las regiones, sabiendo que dicha fuente representa la expresión más significativa de la autonomía política y organizativa de las regiones. Si la potestad legislativa les permite a estos entes manifestar, en los sectores materiales de competencia, su propia orientación política, en la estatutaria les permite autodeterminar los principios de organización, aunque sólo sea en el ámbito de la forma de gobierno delineada por la Constitución. De aquí surge la necesidad de que la potestad estatutaria asuma las características de una autonomía estatutaria sustancial y efectiva.

A pesar de ello, para este fin la solución introducida por los redactores de la Constitución de 1947 resultó en seguida ser insatisfactoria tanto desde el punto de vista sustancial como bajo el perfil de procedimiento.

Por lo que respecta al objeto de la potestad estatutaria, el artículo 123 de la Constitución reducía excesivamente los márgenes de autonomía institucional, estableciendo que dicha fuente debía marcar las normas correspondientes a la organización interna de las regiones.

Era muy cierto que la materia de la organización interna del ente se interpretaba en sentido amplio y dinámico, hasta el punto de incluir, ade- 
más de la reglamentación del planteamiento, el funcionamiento y las relaciones entre los órganos de la región, también la predisposición y la disciplina de los instrumentos necesario para lograr los propios fines de la región. Del mismo modo el elenco constitucional no tenía naturaleza taxativa, sino que - como precisa la doctrina - se limitaba a identificar el contenido mínimo de los estatutos regionales, pudiéndose muy bien introducir otros perfiles materiales, siempre que correspondieran a la organización interna.

Sin embargo, en la mayor parte de los casos se trató de disposiciones que tenían como fin adecuar la organización interna a principios que ya se aplicaban en las administraciones públicas nacionales, así como de disposiciones de naturaleza fundamentalmente programática destinadas a especificar y actualizar mejor el catálogo de los fines y de los objetivos fundamentales en los que trata de inspirarse la actividad regional. Pero, sobre todo, se pone de manifiesto que de la autonomía estatutaria surgía la posibilidad de identificar los perfiles sustanciales de la forma de gobierno, que fueron determinados de modo homogéneo directamente por el texto de la Constitución.

Además, las regiones encontraban límites no sólo de objeto, sino también de sustancia: de hecho, los estatutos debían estar «en armonía con la Constitución y con las leyes de la República». Se trataba de una formulación reductiva en cuanto a que la expresión "en armonía con la Constitución» se remitía a la necesidad que tienen las regiones de adoptar modelos organizativos que sean coherentes con los principios generales que pueden dimanar de la Constitución y de las principales leyes del Estado que regulan la materia. A su vez, la expresión «en armonía... con las leyes de la República» se debía interpretar en el sentido de que los contenidos de los estatutos no sólo no podían estar en oposición con las actuales disposiciones en las leyes sobre materia regional aludidas directamente por el texto constitucional, sino también - como ha precisado el juez constitucional- principios planteados por el ordenamiento jurídico nacional en materia de organización regional.

Estas limitaciones -que circunscribían la potestad regional haciendo imposible suponer la existencia de planteamientos institucionales diferenciados- sólo se superaron con la Ley constitucional 1/99, que codifica una formulación del objeto de la potestad de autoorganización más amplia y coherente con las exigencias de la autonomía. Esta orientación surge, sobre todo, de la interpretación de dos disposiciones: la primera - contenida en el art. 3 - reserva a la fuente estatutaria la competencia 
de determinar tanto la forma de gobierno, como los principios fundamentales de organización y de funcionamiento, aunque sólo sea en el ámbito de los principios contenidos en la propia ley constitucional; la segunda - presente en el art. 2 - prevé un nuevo tipo de legislación regional competente que tiene por objeto la disciplina del «sistema de elección y de los casos de inelegibilidad y de incompatibilidad del presidente y de los demás componentes de la junta regional».

De este modo se codifica el principio de que la autonomía constitucional de los entes implica una diferenciación de sus formas de organización política, superando aquel principio de uniformidad sustancial que, de todos modos, regula la potestad estatutaria de los municipios y de las provincias. Ahora se trata de verificar en qué modo los consejos regionales, renovados recientemente por las elecciones de abril de 2000, utilizarán dicha oportunidad significativa que ofrecen las nuevas disposiciones constitucionales.

\subsection{La potenciación de las formas asociativas y de los instrumentos de colaboración entre los entes locales territoriales}

El sistema de gobierno local, aunque gira en torno a los municipios y las provincias, se presenta hoy mucho más articulado de lo que manifiesta la lectura del dictado constitucional. No sólo porque el legislador ordinario ha instituido nuevos entes locales territoriales, como las comunidades montañesas y las ciudades metropolitanas, sino también porque ha incentivado de diferentes modos la cooperación y la asociación entre los entes locales.

Italia, como es sabido, durante mucho tiempo ha permanecido sustancialmente ajena a cualquier operación de simplificación de la retícula del gobierno local, aunque el problema estaba bien patente. Una característica negativa más de nuestro sistema de poderes locales estaba además constituida por su uniformidad, en el sentido de que todos los entes locales del mismo tipo, independientemente de la dimensión y de la amplitud de sus correspondientes territorios, institucionalmente debían desempeñar las mismas funciones $y$, sustancialmente, se inspiraban en el mismo modelo de organización.

Con objeto de conseguir un planteamiento del gobierno local más funcional y eficaz, en el pasado se habían planteado algunas hipótesis, entre las cuales figuran las siguientes: 
a) reducir el número de administraciones locales mediante su agrupación;

b) transferir las funciones a entes locales de dimensión supramunicipal;

c) incentivar la creación de formas asociativas entre los entes locales;

d) atribuir a las regiones un papel decisorio en la creación de asociaciones o uniones entre municipios y provincias.

Sin embargo, estas hipótesis de reorganización institucional tampoco han resultado practicables.

La primera se topó irremediablemente con la resistencia de las comunidades locales, que se opone decididamente a cualquier propuesta de reducir el número de municipios, viendo en dicha opción una disminución de autonomía y de significativas prerrogativas constitucionales, o bien un ataque a sus tradiciones históricas.

A su vez, la segunda solución se encontró con la ausencia de una orientación unívoca por parte de las fuerzas políticas en cuanto al papel y a las tareas que se deben asignar a las administraciones provinciales.

La cuarta, aunque encontró un fundamento positivo en la legislación vigente, no consiguió afirmarse adecuadamente por los contrastes de orden institucional que existen entre los entes locales y las regiones en cuanto a la distribución concreta de las competencias administrativas.

Por lo tanto, el legislador nacional ha optado por una vía distinta. Sin dejar de lado la posibilidad de simplificar la retícula del sistema de gobierno local - artículos específicos disciplinan el procedimiento para la fusión de los municipios más pequeños (art. 11) y para la revisión de las circunscripciones provinciales (art. 16) - y aunque se atribuye a las regiones - como ya se ha visto en el apartado anterior- un papel significativo en la reorganización del sistema de gobierno local, ha preferido robustecer las formas asociativas entre los entes locales territoriales, pretendiendo un proceso de agregación sobre base voluntaria y de incentivos.

Según el Decreto legislativo 112/98 sobre el otorgamiento de nuevas funciones administrativas a las regiones y a los entes locales, y según la Ley 265/99, que enmienda la Ley 142/90, los procesos de asociación ya no se imponen, sino que se favorecen a través de incentivos adecuados. 
La determinación de los ámbitos territoriales y de las formas asociativas o de cooperación se confía a los propios entes locales afectados, en cuyas relaciones la región ejerce una acción de tipo promocional y facilitador.

En particular el artículo 6, párrafo 6, de la Ley 265/99 ha atribuido a la región la tarea de introducir por ley medidas de incentivación para el ejercicio asociado de las funciones. El objetivo del legislador nacional consiste en hacer "conveniente» para los entes locales la constitución de formas intensas de unificación de los servicios, atribuyendo incentivos diversificados según el grado de integración. Parece evidente que la eficacia de este diseño institucional depende en buena medida de la entidad de los recursos económicos puestos a disposición por las regiones y de los beneficios atribuidos a los municipios que decidan integrar en grado máximo el ejercicio de las funciones administrativas.

A su vez, la Ley 59/97, al delegar en el gobierno el otorgamiento de nuevas funciones y tareas a las regiones y los entes locales, entre los criterios directores había definido la opción de procedimientos e instrumentos de vínculo, incluso permanente, que permitieran la colaboración y la acción coordinada entre los entes locales. Además, esa misma ley había puntualizado que el otorgamiento de las funciones se debía inspirar en el principio de cooperación.

Finalmente, el Decreto legislativo 112/98, más que indicar directamente los instrumentos de enlace entre los distintos entes que componen el sistema de gobierno local, ha preferido reservar dicha tarea a la competencia regional, definiendo sin embargo un procedimiento de formación de los acuerdos de naturaleza participativa, basado preferiblemente en la acción voluntaria de los entes locales afectados.

Con este fin se ha previsto un procedimiento compuesto por las siguientes fases:

$1 .^{\circ} \quad$ las regiones definen niveles óptimos de ejercicio de las funciones que se han de conferir a los municipios, con objeto de favorecer el ejercicio asociado de las funciones de los municipios con menor dimensión demográfica; además, indican el límite temporal dentro del cual se deben establecer los acuerdos o convenios al efecto. Las leyes regionales siempre deben prever instrumentos de incentivación adecuados para favorecer el ejercicio asociado de las funciones;

2. $\quad$ las regiones hacen que esa definición esté precedida por una acción de concertación con los entes locales afectados; 
3. $\quad$ los municipios, en el ámbito de la previsión regional y respetando los tiempos prescritos, definen autónomamente las formas y las metodologías de colaboración y cooperación;

4..$^{\circ}$ si transcurre inútilmente el plazo previsto por la ley regional, la región debe ejercer su propio poder sustitutivo en las formas indicadas por dicha ley.

Evidentemente, tanto los municipios como las regiones, al elegir la forma considerada más apropiada - tanto por lo que respecta a los sujetos con los que establecer la relación de cooperación (municipios, provincias, regiones, administraciones del Estado), como en consideración de las características de las actividades que se tratan de ejercer en comúndeben atenerse a las opciones reguladas por el legislador: concretamente por la Ley 142/90, que habla de convenios, consorcios, uniones de municipios y acuerdos de programas.

El procedimiento delineado por el legislador nacional parece en conjunto respetar tanto la autonomía de los entes locales territoriales, que definen autónomamente las formas y las metodologías de colaboración y cooperación, como de la capacidad directiva de las regiones, que pueden intervenir en caso de inercia con objeto de lograr la finalidad de una acción administrativa eficiente y eficaz.

La Ley 265/99 también atribuye a las regiones un papel específico en la incentivación y la promoción, según programas plurianuales adecuados, de la asociación entre los municipios. Con este fin, las regiones pueden prever en su propio presupuesto un fondo para la incentivación, graduando la distribución de los beneficios en función de la intensidad del proceso de unificación, y privilegiando los planteamientos de integración máxima y los de fusión y unión.

Para superar la posible inercia regional también se introdujo un mecanismo sustitutorio: las regiones están llamadas a adoptar las leyes para la incentivación del ejercicio asociado de funciones dentro de los 18 meses siguientes a la fecha de entrada en vigor de la ley. Si dicho plazo transcurre en vano, el gobierno, dentro de los 60 días siguientes, tras oír a las regiones que no cumplieron y tras la conferencia unificada entre Estado y autonomías locales, procede a dictar la normativa correspondiente, en el respeto a los principios contenidos por la ley, que se aplica hasta la entrada en vigor de la ley regional. 


\section{UN NUEVO PAPEL PARA EL ESTADO CENTRAL}

La evolución de la nueva normativa en materia de autonomías territoriales tiene recaídas significativas e interesantes de orden teórico, que afectan tanto al sistema de las fuentes, como a las propias nociones teóricas de referencia.

En cuanto al primer perfil, se registran novedades no sólo en cuanto a la determinación de las características típicas de las fuentes de autonomía (leyes regionales, estatutos, reglamentos) y de su ubicación en el seno de nuestro sistema legal de fuentes (fuentes atípicas reguladas por el criterio de la competencia), sino también con referencia al carácter suplementario de la normativa estatal en caso de inercia normativa de las regiones y de los entes locales.

A propósito de las segundas, desde el sistema de la legislación más reciente en la materia destaca una nueva concepción del papel del Estado central, que ya no está marcada por los criterios tradicionales de preeminencia y de jerarquía: dicha transformación tiene un reflejo interesante, por ejemplo, en las características y en la función del poder sustitutivo en caso de incumplimientos de obligaciones legales por parte de las autonomías territoriales.

La atención se desplaza del Estado central, entendido como un conjunto organizativo compuesto por ministerios y por entes públicos nacionales, a la organización central de la República, entendida como conjunto de órganos en cuya manifestación de voluntad concurren tanto las instancias estatales como las representativas de las autonomías territoriales. De este modo adquiere una actualidad renovada la distinción tradicional de la doctrina constitucionalista entre el Estado como aparato y el Estado como comunidad: según esta distinción, con esta última expresión se trata de privilegiar la base social de las instituciones así como las realidades institucionales que el constituyente ha marcado con la expresión «república». Por otra parte, el valor comunitario de la autonomías territoriales se obtiene no sólo de la reconstrucción del principio de autonomía, que hemos subrayado al comienzo del presente trabajo, sino también por definiciones legales explícitas, in primis por el dispositivo del artículo 114 de la Constitución, sobre cuya base la República se distribuye en regiones, provincias y municipios.

Esta cuestión destacada justifica la existencia de una contradicción totalmente aparente por la cual, si bien por un lado se tiende a reducir las estructuras y las tareas del Estado central, por otro lado, adquieren relevan- 
cia los instrumentos y los mecanismos destinados a garantizar, con la unificación del ordenamiento, la salvaguardia de los intereses nacionales y la tutela del principio de igualdad, también sobre la base territorial.

Según la aspiración de los constituyentes -expresada plásticamente por el artículo 5 de la Constitución, según el cual la «República una e indivisible reconoce y promociona las autonomías»-, la naturaleza unitaria del Estado y la distribución territorial del poder político no se deben considerar irremediablemente antagonistas, sino, por el contrario, valores complementarios de nuestro planteamiento constitucional. Sin embargo, para que esto se produzca es necesario que a cada uno de estos dos términos se le asigne un valor y un alcance compatibles con la existencia del otro; en otros términos, es necesario que entre ellos se produzca una distribución equilibrada.

La valoración de las autonomías no deslegitimiza las funciones ejercidas centralmente, pero - más bien - impone una recalificación coherente con el convencimiento de que la dimensión unitaria del Estado atribuye al nivel central de la República la función de intervenir, tanto para que las diferencias entre las distintas comunidades regionales no mermen la paridad entre los ciudadanos en cuanto al goce de los derechos fundamentales, como con el fin de realizar el deber de solidaridad.

\subsection{Naturaleza y funciones del poder sustitutivo}

En un sistema en el que, por un lado, las relaciones entre los distintos niveles institucionales no son de tipo jerárquico, sino que deben estar marcadas por un principio de colaboración y de cooperación, pero por otro lado se debe garantizar la funcionalidad conjunta del sistema, adquiere relevancia la atribución al Estado del ejercicio del poder sustitutivo. Sólo que sus finalidades y las modalidades de manifestación se deben reconsiderar y armonizar con el principio constitucional de autonomía.

La noción de intervención sustitutiva se ha estudiado ampliamente en la doctrina administrativa, que ha manifestado dudas sobre su correcta clasificación dogmática, hablando a este respecto de «concepto híbrido». En particular se manifestaba como problema la posibilidad de encuadrar dicha figura en el más amplio genus de los controles administrativos: esto no sólo considerando la dudosa compatibilidad con el principio constitucional de autonomía de las comunidades territoriales y de los entes representativos (BENVENUTI ya afirmaba que la autonomía «significa que el ordenamiento conjunto es la resultante de una suma de ordenamientos 
particulares»), sino también porque, de hecho, el momento del control asume una función preliminar y subordinada con respecto a la fase central del procedimiento, constituida por la intervención sustitutiva de una autoridad superior en caso de inercia. Como ya se ha afirmado, «en el control sustitutivo, la verificación de la inercia tiene un carácter meramente... instrumental en cuanto a la adopción de la medida propiamente dicha, que consiste en la sustitución de una autoridad». Por lo tanto, esta figura ha asumido progresivamente una identidad propia distinta de la del control, terminando por realizar — sobre todo a la luz de la normativa más reciente - tareas de impulso, de garantía de la funcionalidad conjunta del sistema de autonomías: en coherencia tanto con el principio de autonomía como con la lógica cooperativa que debe caracterizar las relaciones entre los distintos niveles institucionales.

Sin embargo, permanece válida la distinción de principio - siempre introducida por la doctrina del Derecho administrativo- entre poder sustitutivo sobre los órganos y poder sustitutivo de actividad: el primero se manifiesta, sobre todo, en caso de disolución de los Consejos y de suspensión o despido de los alcaldes y presidentes; el segundo, a su vez, trata de hacer cumplir, en caso de inercia, actos obligatorios por ley.

Además, otra distinción puede afectar al hecho de que la actividad sustitutiva se traduzca en la adopción de un acto normativo, en particular de la ley regional, o en la adopción de actos administrativos. Si bien en la primera hipótesis el gobierno sustituye directamente a las regiones incumplidoras, en el segundo caso el ente que debe verificar el respeto de las obligaciones legales puede ejercer directamente la intervención sustitutoria o no hacerse sustituir directamente en la adopción del acto, definiendo y nombrando a un comisario ad acta al que concretamente compete sustituir a la región o al ente local incumplidor.

Entra dentro de las intervenciones sustitutorias destinadas al nombramiento de un comisario ad acta el poder sustitutivo de las regiones en sus relaciones con los municipios y las provincias incumplidores.

El artículo 48.2 de la Ley 142/90, que demanda a la competencia legislativa integradora de las regiones la tarea de regular los modos de ejercer el poder sustitutivo, que éste se deba ejercer al darse los siguientes hechos:

a) cuando el alcalde o el presidente de la provincia, una vez transcurrido inútilmente el plazo asignado al consejo, no delibere los nombra- 
EVOLUCIÓN DEL SISTEMA CONSTITUCIONAL DE LAS AUTONOMIAS TERRITORIALES

mientos que son competencia del ente dentro de los 15 días siguientes (art. 36.5);

b) en el caso de que no se apruebe el balance dentro del plazo que establece la ley, o de que falte la adopción dentro del plazo asignado, de las modificaciones que se han de introducir en el balance indicadas por el comité de control, o bien de anulación de la deliberación sobre la adopción del balance (art. 46.10);

c) cuando, en los términos previstos por la ley, para la aprobación del balance de previsión, la junta todavía no haya preparado y aprobado el esquema correspondiente. En este caso, el comité debe nombrar un comisario con la tarea de preparar el esquema de balance y de someterlo a la aprobación del consejo;

d) cuando el consejo no apruebe, en los términos que establece la ley, el esquema de balance preparado por la junta;

e) finalmente, el artículo 48 contiene una cláusula general de cierre del sistema, que prevé la intervención sustitutoria cada vez que los órganos municipales y provinciales omitan el cumplimiento de actos que sean obligatorios por ley.

Son numerosas las situaciones en las que el gobierno sustituye directamente a las regiones que no cumplen la adopción de actos particulares.

El primer tipo de intervenciones sustitutorias ha sido introducido por el legislador en materia comunitaria para suplir la eventual inercia de las regiones en la aplicación de las directivas de la Unión Europea. El respeto puntual y a tiempo de las obligaciones comunitarias ha sido considerado por el mismo juez constitucional como expresión de un interés nacional, incluso en conexión con la responsabilidad internacional del Estado (sentencias $182 / 76 ; 81 / 79)$. En este sentido hay que señalar que el Tribunal Constitucional, durante el juicio sobre la admisibilidad de una solicitud de referéndum para abolir la ley que autorizaba la intervención sustitutoria y suplementaria del Estado, se decidió por la inadmisibilidad de la solicitud, argumentado que «aunque en el actual estado del proceso de integración europea se asiste a una creciente expansión del papel de las autonomías en el contexto del Derecho comunitario, el conjunto de las funciones que el Estado está llamado a ejercer en las relaciones con la Comunidad Europea no se puede eliminar... por oponerse el principio de unidad y de indivisibilidad de la república sancionado por el artículo 5 de la Constitución» (sentencia 20/97). 
A continuación, la intervención sustitutiva del Estado se ha ampliado a distintos sectores materiales que, aunque entran dentro de la potestad legislativa y administrativa de las regiones, destacan por una particular relevancia y por la presencia simultánea de intereses unitarios que se han de salvaguardar en caso de inercia de las administraciones competentes. Sobre todo, este caso se da en materia ambiental, sanitaria, energética y paisajistica.

Por ejemplo, de vez en cuando se ha considerado conforme a la Constitución el ejercicio de una intervención sustitutoria en el caso de que falte la identificación de las áreas con un elevado riesgo ambiental (sentencia 210/87), de que falte la aprobación de los planes urbanísticos-territoriales para la valoración ambiental y la definición de las áreas sometidas al vínculo paisajístico (sentencia 36/95), de que no se haya aprobado el programa trienal para las áreas naturales protegidas (sentencia 366/92), de que falte la definición de la cuencas energéticas (sentencia 483/91), de medidas sanitarias destinadas a la lucha contra el SIDA (sentencia 37/91) y de la falta de adopción de medidas preventivas destinadas a la defensa del suelo (sentencia 85/90).

Sin embargo, consideramos que desde el punto de vista institucional presentan una especial relevancia los casos de intervención sustitutoria previstos por la legislación más reciente en el tema de la distribución de las funciones administrativas entre los distintos niveles institucionales y de reorganización del sistema de gobierno local. En este punto, las principales hipótesis de sustitución en caso de inercia en la aprobación de leyes regionales se pueden definir en lo siguiente:

\section{a) Poder sustitutorio del Estado en caso de inercia de las regiones}

Según el artículo 5 del Decreto legislativo 112/98, en el supuesto de que exista inactividad que implique el incumplimiento de las obligaciones derivadas de la pertenencia a la Unión Europea, o peligros de grave perjuicio para los intereses nacionales, el Presidente del Consejo, a propuesta del ministro competente en la materia, debe fijar a la región incumplidora un plazo adecuado para cumplir. Una vez transcurrido inútilmente dicho plazo, el Consejo de ministros, una vez oído al ente incumplidor, nombra un comisario que actúa por vía sustitutoria.

En caso de urgencia absoluta, el Consejo de ministros puede dar lugar inmediatamente al nombramiento del comisario, salvo que someta el procedimiento a la conferencia Estado-ciudades autonómicas locales (que en 
este caso se amplía con representantes de las comunidades montañesas), que puede solicitar un nuevo examen.

La legislación regional sobre actuación del Decreto legislativo 112/98, a su vez, ha introducido formas de poder sustitutorio en las relaciones con las entidades locales incumplidoras, limitándose a las funciones conferidas a ellas por la región.

\section{b) Poder sustitutorio del Estado en caso de que las regiones no} realicen la definición de las funciones que se han de conferir al sistema de los entes locales

En caso de que las regiones no adopten las leyes de definición puntual de las funciones que se han de conferir a los entes locales, y las que han de mantener a la cabeza de la región, el artículo 4.5 de la Ley 59/97 autoriza al gobierno, una vez oídas las regiones incumplidoras, a aprobar uno o más decretos legislativos de distribución de funciones entre las regiones y los entes locales, cuyas disposiciones se aplican hasta la fecha de entrada en vigor de la ley regional.

Este poder sustitutorio ha sido ejercido por el gobierno concretamente con el Decreto legislativo 96/99, que - con un único acto destinado a todas las regiones incumplidoras - ha dictado las disposiciones sobre la distribución de las funciones administrativas entre las regiones y los entes locales. El procedimiento aplicado plantea problemas concretos de legitimidad constitucional, desde el momento en que el gobierno ha adoptado el decreto sin oír formalmente a las distintas regiones incumplidoras, limitándose a conminarlas en la reunión de la Conferencia Estado-regiones: de hecho, ha sido objeto de una cuestión de legitimidad constitucional por vía de juicio principal, que actualmente está examinando el Tribunal Constitucional.

c) Poder sustitutorio de las regiones en cuanto a la inercia de los entes locales para constituir formas asociativas para el ejercicio en común de funciones administrativas

Según el artículo 3.2 del Decreto legislativo 112/87, los municipios deben determinar autónomamente los sujetos, las formas y las metodologías para el ejercicio asociado de las funciones administrativas en los términos que indican las leyes regionales. Transcurrido inútilmente dicho 
plazo, la región ejerce el poder sustitutorio en las formas establecidas por la ley regional.

A pesar de la diversidad de los asuntos regulados, parece posible desarrollar algunas consideraciones resumidas:

a) Sobre todo, se pone de manifiesto que los efectos del poder sustitutorio tienen una duración limitada en el tiempo, y no prejuzgan las posibilidades que tienen las regiones de ejercer concretamente su propia autonomía legislativa. El legislador se ha apresurado para evitar que la intervención del Estado comprima o prejuzgue la esfera de las atribuciones de los sujetos autónomos, tratando de desempeñar una función de mero apoyo y garantía de la funcionalidad conjunta del sistema. Las normas estatales tienen un valor explícitamente provisional, en cuanto que automáticamente quedan sustituidas por las regionales en cuanto se adoptan. De hecho, el gobierno, sustituyendo a las regiones incumplidoras, evita que el procedimiento de distribución de las competencias entre los distintos niveles institucionales se interrumpa con graves consecuencias para el funcionamiento regular del sistema; al mismo tiempo estimula a las regiones para ejercer en concreto sus propias competencias. Esto se produce en cualquier caso, tanto si aprueban una ley cuyas disposiciones derogan las producidas por la fuente estatal primaria, como si deciden no aprobar ninguna normativa, en cuyo caso se deciden por mantener la permanencia de las normas estatales en el seno del ordenamiento jurídico regional.

Se está en presencia de un interesante caso de supletoriedad transitoria del Derecho estatal en su relación con el regional, cuyos matices bajo el perfil del sistema de las fuentes se detallarán en el apartado siguiente.

b) En segundo lugar, el ente incumplidor debe ser conminado a título preventivo. El titular del poder sustitutorio debe fijar un plazo adecuado en el tiempo, dentro del cual se pueda proceder efectivamente. Esta condición es importante, pues la intervención sustitutoria debe constituir un instrumento excepcional, desde el momento en que determina una modificación de la legitimación para actuar, y a él se debe recurrir como extrema ratio.

En otras palabras, como repetidamente ha precisado el Tribunal Constitucional, el procedimiento de ejercicio del poder sustitutorio se debe disciplinar en coherencia con el conocido principio de la leal colaboración: lo cual, en el caso que nos ocupa, se manifiesta bajo la condición de que la intervención sustitutoria tenga lugar, y no sólo después de haber conminado para que se proceda, sino también después de haber oído a las 
regiones o a los entes locales incumplidores en cuanto a las razones de la falta de cumplimiento (sentencias 830/88; 37/91; 483/91; 49/91; 21/91; $85 / 90 ; 427 / 92)$.

c) En tercer lugar, el poder sustitutorio debe tener una base legal, más aún, debe estar explícitamente previsto y regulado por una ley. En este punto el juez constitucional ha excluido que sea posible ampliar la acción supletoria del Estado a hechos distintos de los definidos por el legislador sobre la base de un acto no legislativo del gobierno (sentencia 338/89).

d) En cuarto lugar, la inercia regional - para legitimar una intervención sustitutoria - debe tener en cuenta la falta de adopción de actos sometidos a términos perentorios, cuya omisión pondría en serio peligro intereses confiados a la responsabilidad final del Estado. Dicho en otros términos, hay que tratar tanto de que ejerzan las funciones vinculadas al an y en el quando, como de funciones destinadas a defender los intereses constitucionalmente tutelados o de importancia constitucional (sentencias $483 / 91 ; 85 / 90 ; 386 / 91)$.

e) Finalmente, el órgano al que compete el poder sustitutorio debe ser un órgano del gobierno central. En consecuencia, el juez constitucional ha considerado que no es conforme a la Constitución una normativa que asignaba la intervención sustitutoria al comisario gubernamental presente en la capital regional. Sin embargo, subsisten dudas sobre si el órgano debe ser necesariamente definido en el Consejo de ministros, o si también puede establecerlo el ministro competente en la materia. De todos modos, pese a lo delicado del poder atribuido, hasta el punto de que representa una derogación de la distribución constitucional de las atribuciones entre el Estado y las regiones, en nuestra opinión sería preferible que la intervención sustitutoria fuese deliberada por el órgano colegial del gobierno.

\subsection{La supletoriedad de la normativa estatal y la afirmación de la noción de norma cedible}

Las relaciones entre el ordenamiento jurídico estatal y el principio constitucional de autonomía, si se proyectan en el sistema de las fuentes del Derecho, generan problemas tanto de encuadramiento teórico, como de determinación concreta de las normas efectivamente aplicables en caso de antinomias normativas. Esta situación se ha manifestado en el ordenamiento español, sobre todo en cuanto a la interpretación del artícu- 
lo 149.3 de la Constitución en relación con la conocida cláusula de supletoriedad; sin embargo, en Italia ha dividido la doctrina la determinación de los efectos que el cambio de la normativa estatal produce en las relaciones con las fuentes de autonomía (estatutos regionales, leyes regionales, estatutos municipales y provinciales, y reglamentos locales).

En general, se puede afirmar, anticipando las conclusiones a las que en definitiva hemos llegado - sobre todo en virtud de la jurisprudencia del Tribunal Constitucional, hecha propia y codificada por el legislador-, que los criterios para la solución de las autonomías normativas que se han de aplicar en las relaciones entre ordenamientos policéntricos y de ordenación paritaria son esencialmente los de la abrogación y la vigencia provisional de la normativa estatal.

Sobre todo, hay que considerar que el principio de autonomía de las comunidades territoriales modera el principio de la primacía del Derecho estatal, por lo cual, con objeto de encuadrar las relaciones entre las leyes estatales y las fuentes de autonomía, no es necesario remitirse al criterio de jerarquía, sino al de competencia. Sin embargo, la aplicación rígida y esquemática del criterio de la competencia acabaría por determinar consecuencias negativas en la operatividad concreta del sistema, sobre todo en lo que concierne a la certidumbre del ordenamiento jurídico.

De hecho, siempre que se trata de aplicar con rigor el principio de competencia se tendría que llegar a la conclusión de que la introducción en el ordenamiento jurídico estatal de nuevas normas (ya sean estatales o comunitarias) incompatibles con las vigentes en los ordenamientos autonómicos determinaría la ilegitimidad de la normativa local, pero no podría determinar la sustitución automática de las nuevas normas estatales por las anteriores normas locales. Éstas seguirían siendo eficaces hasta que no sean modificadas por los organismos competentes de las autonomías territoriales, o se declarasen ilegítimas por los jueces.

En otros términos se produciría una situación de ilegitimidad producida. Los inconvenientes de este encuadramiento teórico - por demás plenamente coherente con el principio constitucional de autonomía- se pueden resumir en el hecho de que para depurar el sistema de las normas que se hayan vuelto ilegítimas es necesario espera a la intervención reformadora de las entidades autónomas -con el necesario ejercicio del poder sustitutorio en caso de inercia regional o de los entes locales-, o a una declaración de ilegitimidad por parte del Tribunal Constitucional (en cuanto a los estatutos y las leyes regionales) o del juez administrativo (en cuanto a los reglamentos y los estatutos municipales y provinciales). 
Para evitar estos inconvenientes se ha considerado que el contraste se podía resolver remitiéndose a un criterio distinto al de la competencia, según el cual el cambio de los principios estatales determina la abolición de la normativa regional y local incompatible con ellos. Dicho de otro modo, el legislador estatal, dictando principios nuevos, deroga las normas incompatibles, sustituyéndolas.

Pero también en este caso la solución no puede resultar satisfactoria desde el momento en que el principio de autonomía quedaría sustancialmente vulnerado en uno de sus elementos cualificadores, constituido por la autonomía normativa. Por lo tanto, la jurisprudencia del Tribunal Constitucional primero, y el legislador después, han optado por una solución intermedia formada por el criterio según el cual, en el ámbito de las antinomias entre normas estatales y normas locales, las primeras derogan a las segundas, pero sustituyéndolas sólo de modo transitorio, con coherencia y con la certidumbre del ordenamiento jurídico general, sobre cuya base la normativa estatal resulta competente para regular una determinada materia de ámbito regional o local, pero dichas normas son aplicables por vía transitoria mientras que la fuente competente no ejerza sustancialmente su propia competencia normativa, procediendo a sustituir la normativa (regional y local) que haya resultado ser ilegítima.

Esta última solución tiene la ventaja de asegurar una mayor certidumbre del Derecho y encuentra un fundamento legislativo puntual.

En el caso de las relaciones entre leyes estatales y fuentes regionales es necesario hacer referencia al artículo 10 de la Ley 62/53, según el cual «las leyes de la República que modifican los principios fundamentales derogan las normas regionales que se opongan a ellas. Los consejos regionales deberán incluir en las leyes regionales las modificaciones consiguientes y necesarias dentro de los 90 días siguientes». Con esta disposición se considera que las dos fuentes concurren en el mismo campo material y que, más aún, la ley estatal está provisionalmente por encima de la regional: en consecuencia, el legislador estatal, al dictar nuevos principios, derogará las normas regionales incompatibles y podrá establecer la disciplina de detalle destinada a regular la materia a título provisional.

En cuanto a las relaciones entre las leyes estatales y las fuentes locales de autonomía es necesario, sin embargo, remitirse a la Ley 265/99, que introdujo un párrafo 2-bis en el artículo 4 de la Ley 142/90, según el cual la entrada en vigor de las leyes que modifiquen los principios en materia de ordenamiento de los municipios y de las provincias, y de disciplina del ejercicio de las funciones, deroga las normas estatutarias incompatibles 
con dichos principios. Ese mismo artículo añade que los consejos municipales y provinciales deben adecuar los estatutos dentro de los 120 días siguientes a la fecha de entrada en vigor de dichas leyes.

Por lo tanto, parece que se ha optado por un sistema que prevé la inmediata derogación de las normas incompatibles con los nuevos principios de la legislación estatal, pero también la provisionalidad de la normativa estatal hasta que se produzca la adecuación de los estatutos dentro del plazo dictado por la ley: resulta evidente que, una vez entradas en vigor las nuevas disposiciones estatutarias, las normas estatales generales dejan de ser directamente aplicables.

Si los municipios y las provincias no modifican sus estatutos, la normativa estatal seguirá regulando la materia, pero este efecto se producirá como consecuencia de una opción asumida autónomamente por el ente local: en este caso también se puede hablar de ejercicio - aunque sea negativo- de la propia competencia normativa.

De todos modos, esta solución no se presenta en absoluto como resolutiva. De hecho, es necesario considerar que la normativa estatal, sobre todo la que tiene por objeto perfiles de organización y de ordenamiento, no siempre se puede considerar autoaplicativa, es decir, capaz de ser aplicada automáticamente, sin que sea necesaria una intervención de especificación o de adaptación por parte de las autonomías territoriales. Del mismo modo tampoco se dejan de lado algunas graves consecuencias de orden práctico que se derivarían de una modificación automática de las normas de organización, siempre que las previsiones específicas contenidas en las fuentes locales se sustituyeran por normas generales destinadas indistintamente a todas las administraciones públicas o a todos los entes locales que pertenecieran a la misma tipología. De hecho, en muchos casos los principios generales se deben adaptar al contexto de organización.

Una solución diferente a este mismo problema ha sido adoptada para regular las relaciones entre la normativa estatal general y las leyes de la región de Trentino-Alto Adige y las correspondientes provincias de Trento y de Bolzano.

Según el artículo 2 del Decreto legislativo 266/92, por lo que respecta a las relaciones entre las leyes regionales del Trentino-Alto Adige (y las provincias autónomas de Trento y Bolzano) y las leyes estatales, los actos legislativos estatales que establecen principios y normas que constituyen límites para la potestad legislativa regional o provincial no encuentran una aplicación inmediata en el territorio de la región, sino que para ésta, y 
EVOLUCIÓN DEL SISTEMA CONSTTTUCIONAL DE LAS AUTONOMIAS TERRITORIALES

para las provincias autónomas en materia de su competencia, implican la obligación de adecuar los ordenamientos respectivos dentro de los seis meses siguientes a la publicación de las normas estatales en la «Gazetta Ufficiale» (o en el plazo más amplio establecido eventualmente por las normas en cuestión).

Durante este período se siguen aplicando las disposiciones legislativas regionales y provinciales existentes con anterioridad. Transcurrido este plazo, dentro de los noventa días siguientes a su vencimiento las disposiciones legislativas (regionales o provinciales) que no sean adecuadas pueden ser impugnadas por el Presidente del Consejo, previa deliberación del Consejo de ministros, ante el Tribunal Constitucional. Como consecuencia de la anulación por parte del Tribunal Constitucional de las leyes regionales o provinciales se aplican las leyes del Estado hasta que los legisladores regionales y provinciales intervengan para disciplinar de nuevo la materia.

Se trata de una solución apreciable y adecuada dado que, por un lado, permite respetar la autonomía de los entes y, por otro, a través de la aplicación transitoria de las normas estatales de detalle permite superar el problema de la inercia de las administraciones locales.

En conclusión, tratando de aclarar esta intrincada maraña con algunas consideraciones a modo de resumen, hay que indicar que el conjunto de la temática de las relaciones entre las fuentes en ordenamientos dirigidos por el principio constitucional de autonomía se debe afrontar con soluciones articuladas que tengan en cuenta las diferentes situaciones. Según la temática que se pueda considerar, se puede hacer referencia tanto a la figura de la derogación como a la constitucionalidad que haya tenido lugar, optando en cada ocasión por la solución que mejor asegure el principio de la certidumbre del derecho.

Con este fin se puede recordar que:

a) en caso de normativa estatal de detalle que intervenga en un sector todavía no disciplinado por las fuentes de autonomía, se puede considerar aplicable la normativa estatal, pero debe ceder en cuanto entren en vigor las normas producidas por las fuentes locales;

b) en caso de normativa estatal de detalle que intervenga en un sector ya disciplinado por las fuentes de autonomía, actúa plenamente el criterio de la competencia, por lo que se deben seguir aplicando las normas producidas por las fuentes de autonomía; 
c) en caso de normativa estatal con principio de autoaplicación, las normas estatales derogan a las locales que sean incompatibles y las sustituyen, aunque sea de modo provisional;

d) en caso de normativa estatal que no tenga el principio de autoaplicación, las normas estatales determinan la ilegitimidad de las normas locales, que deben ser anuladas por el juez o sustituidas por las fuentes de autonomía.

Sin embargo, en esta última hipótesis se plantea un problema que no tiene fácil solución, y que se puede resumir en el interrogante sobre las consecuencias que se derivan de la falta de respeto por parte de las autonomías territoriales al plazo necesario para adecuar su propia normativa a las nuevas disposiciones estatales genéricas. ¿Quid iuris en ausencia de inercia?

Se pueden plantear dos caminos diferentes en función de que se considere que se está ante un caso de disolución del órgano incumplidor - siempre que se considere que la inercia representa una «violación grave de la ley»-, o bien de ejercicio del poder sustitutorio. En esta hipótesis hay que recurrir a los procedimientos y a las garantías que se mencionaban en el apartado anterior. 